\title{
Assessment of shear wave velocity concept on the site specific analysis and its effects over performances of building codes
}

\author{
Ersin Güler (iD)1, Kamil Bekir Afacan* (iD)1 \\ 1 Department of Civil Engineering, Faculty of Engineering and Architecture, Eskişehir Osmangazi University, \\ Eskişehir (Turkey), eguler@ogu.edu.tr; kafacan@ogu.edu.tr \\ *Correspondence: kafacan@ogu.edu.tr
}

Received: 18.02.2021; Accepted: 13.12.2021; Published: 31.12.2021

Citation: Güler E., Afacan K.B. (2021). Assestment of Shear Wave Velocity Concept on the Site Specific Analysis and Its Effects over Performances of Building Codes. Revista de la Construcción. Journal of Construction, 20(3), 527-543. https://doi.org/10.7764/RDLC.20.3.527.

\begin{abstract}
Earthquakes' effects on the ground especially to superstructures vary depending on the local site conditions. As the seismic waves move towards the surface, the dynamic behavior is affected by the depth of the bedrock, layer thickness, and the soil type. Site specific soil behavior analyses are carried out to estimate the seismic force spread from the bedrock to the ground along the soil layers and to determine the spectral properties of the site. During the transmission of the wavelength, the amplitude and frequency content change depending on the properties of the soil layers. Both the alteration of the dynamic properties of soil layers and the earthquake characteristics must be analyzed in order to predict the ground surface behavior. Turkey is one of the most important earthquake prone country in Europe and it is crucial to reduce any possible damage as a result of seismicity by taking the necessary measures. This study focuses on a region near North Anatolian Fault which is one of seismically active faults in Yalova region in Turkey. The goal is to understand the nonlinear site specific behavior along with the equivalent linear option using two boring data with similar shear wave velocity and site class. Eleven different earthquakes were chosen for the analysis. The fault type and the soil class are the main characteristics to determine those records. The spectral behaviors of the ground surface were obtained from different models and they were compared with three different building codes (the new Turkish Building Code (TBC 2018), the Eurocode8 (EC8) and the International Building Code (IBC)). Analysis show that 1) the performance of the building codes vary a lot to predict the surface behavior, 2) equivalent and nonlinear site response differ in terms of short and long period spectral behavior and 3) the determination of site classes from shear wave velocity solely may not be sufficient to understand the propagation of the wave and sandy or clayey behavior should also be considered in design purposes.
\end{abstract}

Keywords: site specific analysis, amplification, TBC 2018, EC8, IBC.

\section{Introduction}

Researchers have carried out so many studies regarding the damages and loss of life caused by earthquakes and targeted on different ways to minimize their effects (Zacchei \& Molina, 2019; Habibi \& Jami, 2017; Vahdani et al., 2019; Choi \& Stewart, 2005; Harmon et al. 2020; Stewart et al., 2020; Harmon et al., 2019; Stanko et al., 2019; Dikmen \& Tan, 2018; Bouckovalas et al., 2016; Aksoylu et al. 2020). In order to determine the earthquake characteristics that will occur on the surface of the local soil profile, soil amplification analysis is conducted in line with the local seismic hazard assessments. Seismic movements occur for different reasons and undergo changes from the bedrock to the ground by being affected by local site conditions, depending on the soil type and dynamic properties. The wavelength is transmitted to the surface either 
by dampened or amplified. This increase in the amplitude of the earthquake waves passing through the soil layers has been defined in the literature as soil amplification (Kaptan \& Tezcan, 2012; Ansal et al., 2011; Horri \& Mousavi, 2019). Intensified earthquake forces transmitted to the foundation increases the deformation levels on the frame elements and results in possible local or structural collapse. A small magnitude bedrock acceleration may scale up several times in some regions due to local conditions and cause very severe damage (Kramer, 1996). Mexico City Earthquake, which occurred in 1985, Kocaeli and 1989 Loma Prieta Earthquakes that occurred in 1999 are the very first examples of the soil amplification effect (Liu \& Dobry, 1997; Toksoz et al., 1999).

It is important to know the properties of the earthquake as well as the soil microstructure, therefore its dynamic behavior, in the investigation of the amplification effect of soils. For the site specific analysis to be made for a specific field for design purposes, earthquakes are selected according to the characteristics of the region such as fault type and local soil conditions (i.e. soil class). Countries live with earthquakes have regulations (building codes) to outline the design processes and soil is generally represented by shear wave velocity, corrected SPT-N values or undrained strength of upper $30 \mathrm{~m}$ profile. Using the soil class and desired ground motion levels, codes offer design spectra for structures to be built on the surface with the help of seismic maps. Moreover, they also describe how the earthquake acceleration records can be selected, scaled and the spectral behavior is obtained for site specific analysis (TEC, 2018; EC 8, 2004; IBC, 2018).

Acceleration time series to be used in the site specific response analysis can be obtained by three different ways. These options are artificially produced acceleration records, simulated records and real earthquake motions (Özdemir \& Fahjan, 2008; Fahjan, 2008). Building regulations suggest sets of rules in order to select and scale earthquakes that comply with the seismological conditions of the site and region in order to understand the motion propagation through a soil column. Original earthquake data recorded any station can be scaled either in the time domain or frequency domain. Two main aspects derive which method should be used: 1) Target peak ground acceleration 2) Target design spectrum. For the time domain approach, only the amplitudes of the acceleration time series are modified without changing the frequency content of the record whereas the frequency content of the ground motion is changed to find a good match to the design acceleration spectrum in the frequency domain application (Özdemir \& Fahjan, 2007; Fahjan, 2008).

Other phenomenon that need to be determined in the site-specific analysis is the ground response spectra. The concept of the spectra acceleration is mainly about the reflecting earthquake properties to be used in the design of structures (Ansal et al., 2011). The average spectrum that passes through the response spectra created by the analysis using different acceleration scenarios. Efforts to evaluate and increase the performance of the analysis for building code regulations are still ongoing work and being developed (Sönmezer \& Çeliker, 2020; Pitilakis et al., 2012; Pitilakis et al., 2013; Pitilakis et al., 2004).

In this study, two different borings that are near North Anatolian Fault Line which is an active seismic zone were used to assess the ground response analysis. These logs are considered to be unique since the shear wave velocity profiles are very similar but the layering is a bit different. After constructing the soil dynamic behavior through the soil column, 11 different motions scaled from real earthquakes matching the seismology of the region were conducted to the soil profiles to get the surface behavior. The number of earthquakes has been determined as specified in the regulations (TEC, 2018; EC 8, 2004; IBC, 2018). The analyses were completed using the DeepSoil v6.1 (Hashash et al., 2016) in terms of equivalent linear and non-linear approaches. Finally, the results were compared with three different regulations

\section{Determining the site-specific motions}

\subsection{Selection and scaling of earthquake records}

Real earthquake records can be scaled in order to be used in the site specific analysis in accordance with a given design acceleration spectrum. The criteria used to select the true strong ground motion record suitable for the design in a particular region should couple with geological and seismological conditions. The magnitude of the earthquake, the type of faulting, the distance of the working area from the nearest fault, the direction of movement, local soil conditions and the spectral content of the record are the most important of these conditions (Özdemir \& Fahjan, 2007; Fahjan, 2008). 
The response spectrum obtained as a result of the analysis made from earthquake acceleration records is difficult to be compatible with the design spectra defined in the regulations. Instead, it is more convenient to select some number of acceleration records as base motions specified in the regulations and compare the average of the ground spectra belonging to analysis conducted with these acceleration records. In order to start this process, acceleration records need to be scaled and there are various methods to increase or ensure compliance.

Two different methods are generally used in the literature: the time domain and frequency domain based methods (Kayhan, 2012). Regarding scaling in the frequency domain, it is based on the derivation of a motion similar to the original record, which almost matches the design acceleration spectrum observed from the acceleration recorded during the earthquake. In this method, the selected real earthquake record is filtered in the frequency domain by the ratio of the design acceleration spectrum to the behavior spectrum of this record. Throughout the whole method, the Fourier phases of motion remain unchanged. Later, the spectral behavior in the obtained frequency domain area is converted to time domain area to get the target design spectrum for the scaled version. It is checked whether this behavior spectrum adequately matches the design acceleration spectrum in the desired period range. If the match is not sufficient, the steps are repeated until the desired match is achieved (Özdemir \& Fahjan, 2007).

Certain criteria for the selection of earthquakes have been published in the regulations determined by the countries for the design of the buildings. Three building codes were considered in this study in pursuance of selecting the earthquake data and the codes are: Turkish Building Code (TBC 2018), Eurocode8 (EC8) and International Building Code (IBC). The new Turkish Building Code has set some certain rules about how to select records to be used in the analysis. Accordingly, it states that if there are enough number of real earthquake data occurred in/around the specific area, they must be used; however, in cases where an adequate number or quality of earthquake record selection cannot be found, simulated ground motion records in the time domain can be used instead. In regard to selecting records, seismic source, wave propagation and local soil features of the site should be taken into consideration. The minimum number of earthquake records to be selected for one or two-dimensional analysis shall be at least eleven. The number of records from the same earthquake should not exceed three (TEC, 2018). Similar rules can be found in International Building Code, as well.

Another building code regarded in this study is the Eurocode and it splits into two main parts as buildings and bridges. The regulation offers that 1) at least three earthquake acceleration records should be used for buildings, 2) the average of the corresponding spectral acceleration values of the earthquake ground motion record at $T_{0}$ should not be less than $A_{0} g$ and 3) the average of the spectral acceleration values to be constructed for the 5\% damping ratio should fall into certain periods. For this interval, the spectral acceleration of the motion should not be less than $\% 90$ of the elastic spectral acceleration values defined in the regulation (EC8, 2004). For the sake of selecting of record in this study, it will be presented later that the model parameters to be used for simulations are compatible with the actual earthquake records recorded in terms of seismology and the site conditions.

Table 1. Vs,30 values of according to soil type.

\begin{tabular}{cccc}
\hline Class & TBC $\mathrm{V}_{\mathrm{s}, 30}(\mathrm{~m} / \mathrm{s})$ & $\mathrm{EC} 8 \mathrm{~V}_{\mathrm{s}, 30}(\mathrm{~m} / \mathrm{s})$ & $\mathrm{IBC} \mathrm{V}_{\mathrm{s}, 30}(\mathrm{ft} / \mathrm{s})$ \\
\hline $\mathrm{A}$ & $>1500$ & $>800$ & $>5000$ \\
\hline $\mathrm{B}$ & $760-1500$ & $360-800$ & $2500-5000$ \\
\hline $\mathrm{C}$ & $360-760$ & $180-360$ & $1200-2500$ \\
\hline $\mathrm{D}$ & $180-360$ & $<180$ & $600-1200$ \\
\hline $\mathrm{E}$ & $<180$ & & $<600$ \\
\hline $\mathrm{F}$ & & & \\
\hline
\end{tabular}

The site conditions are generally evaluated using the 'soil classes' depending of their average corrected SPT blow count, undrained strength and the shear wave velocity of the upper $30 \mathrm{~m}$ of the soil column. The $\mathrm{Vs}, 30$ is the most used one in order to classify the soil type and the typical values of different building codes are presented in Table 1. This characteristic is also important for the selection process. 


\subsection{Selected earthquake records and features}

The northern branch of the North Anatolian Fault zone, which is the main source for the East Marmara Earthquake, consists of strike-slip segments that are the Sapanca-Gölcük segment, Izmit- Karamürsel segment and Yarimca-Yalova segment (Koç, 2007). The strike-slip faults are vertical or near-vertical structures and the dominant motion is parallel to the direction of the fault. Many different terms are used for the faults of the same character depending on their environment characteristics.

Table 2. Selected earthquakes (Peer, 2019).

\begin{tabular}{|c|c|c|c|c|c|c|c|c|c|}
\hline No & Earthquake & Year & Station & $\mathrm{R}_{\mathrm{jb}}(\mathrm{km})$ & $\mathrm{R}_{\text {rup }}(\mathrm{km})$ & Fault type & $\begin{array}{l}\text { Mag. } \\
(\mathrm{M})\end{array}$ & $\begin{array}{l}\mathrm{V}_{\mathrm{s} 30} \\
(\mathrm{~m} / \mathrm{s})\end{array}$ & Scale Factors \\
\hline 1 & Imperial Valley-02 & 1940 & $\begin{array}{c}\text { El Centro Array } \\
\# 9\end{array}$ & 6.09 & 6.09 & Strike Slip & 6.95 & 213.44 & 2.10 \\
\hline 2 & El Alamo & 1956 & $\begin{array}{c}\text { El Centro Array } \\
\# 9\end{array}$ & 121 & 121.7 & Strike Slip & 6.8 & 213.44 & 3.90 \\
\hline 3 & Imperial Valley-06 & 1979 & Bonds Corner & 0.44 & 2.66 & Strike Slip & 6.53 & 223.03 & 0.99 \\
\hline 4 & Morgan Hill & 1984 & Gilroy Array \#4 & 11.53 & 11.54 & Strike Slip & 6.19 & 221.78 & 2.65 \\
\hline 5 & Kobe_Japan & 1995 & Abeno & 24.85 & 24.85 & Strike Slip & 6.9 & 256 & 2.57 \\
\hline 6 & Kocaeli_Turkey & 1999 & Afyon Bay & 207.8 & 207.8 & Strike Slip & 7.5 & 225.6 & 2.94 \\
\hline 7 & Chi-Chi_Taiwan-04 & 1999 & Chy026 & 39.63 & 39.66 & Strike Slip & 6.2 & 226.01 & 3.24 \\
\hline 8 & $\begin{array}{c}\text { Nenana Mountain__ } \\
\text { Alaska }\end{array}$ & 2002 & Anchorage - DOI & 272.8 & 272.8 & Strike Slip & 6.7 & 212.48 & 3.81 \\
\hline 9 & Parkfield-02_CA & 2004 & $\begin{array}{l}\text { Parkfield - Froe- } \\
\text { lich }\end{array}$ & 1.85 & 3.19 & Strike Slip & 6 & 226.63 & 1.30 \\
\hline 10 & $\begin{array}{c}\text { Darfield_ New Zea- } \\
\text { land }\end{array}$ & 2010 & Hulverstone Drive & 72.75 & 73.31 & Strike Slip & 7 & 206 & 3.39 \\
\hline 11 & $\begin{array}{c}\text { El Mayor } \\
\text { Cucapah_Mexico }\end{array}$ & 2010 & Winterhaven & 25.4 & 25.4 & Strike Slip & 7.2 & 229.92 & 3.64 \\
\hline
\end{tabular}

In order to evaluate the site response behavior, base motions were needed and as the TEC-2018 states at least eleven records should be used in such analysis. Therefore, eleven earthquake records were selected that match the site characteristics in terms of the type of the fault (strike-slip faults for this case) and the $\mathrm{Vs}, 30$ in a range of $206-230 \mathrm{~m} / \mathrm{s}$. The details of the selected motions are shown in Table 2. As seen in the table, they are all big magnitude earthquakes with different distances from all over the world happened in different times. There is one point here to underline is that some earthquake motions were selected more than $100 \mathrm{~km}$ because the PEER database had only limited ground motions with the target $\mathrm{Vs}, 30$ range and the fault type. The scaled versions of the motions will be presented later.

\section{Analysis of site-specific soil behavior}




\subsection{Geology and tectonic of study area}

North Anatolian Fault, which is one of the most active fault lines in Turkey (NAFZ) continued east to west with earthquake fracture. Most recently, Kocaeli $(M=7.6)$ and Duzce $(M=7.1)$ Earthquakes happened in 1999 in this region. NAFZ is divided into two from the province of Bolu and its northern branch (North NAF Zone) passes through the Marmara Sea over the Gulf of Izmit. It then connects to the Ganos Fault and reaches the Aegean Sea. The southern branch (South NAF Zone) passes through the south of Iznik Lake and reaches Gemlik Bay. Between these two main branches, there are faults of different sizes and types from the names of Yalakdere, Orhangazi, Yalova, Altınova, Çınarcık and Esenköy (Figure 1).

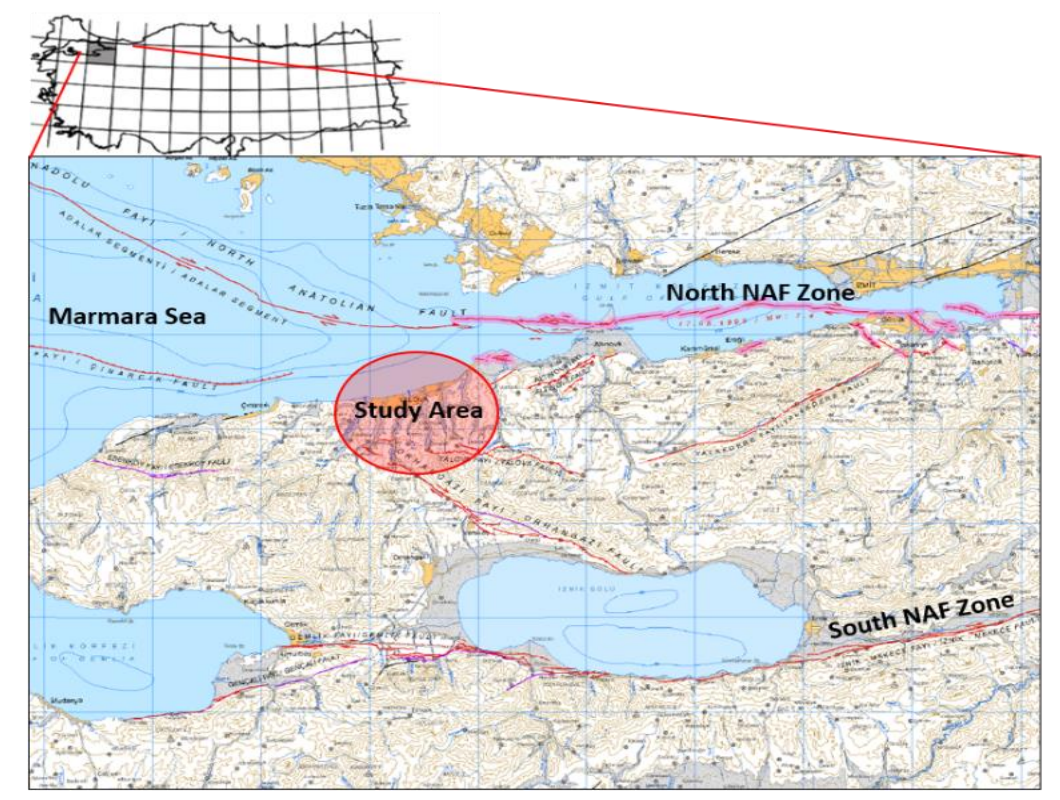

Figure 1. Study zone and active fault lines (Emre et al., 2011).

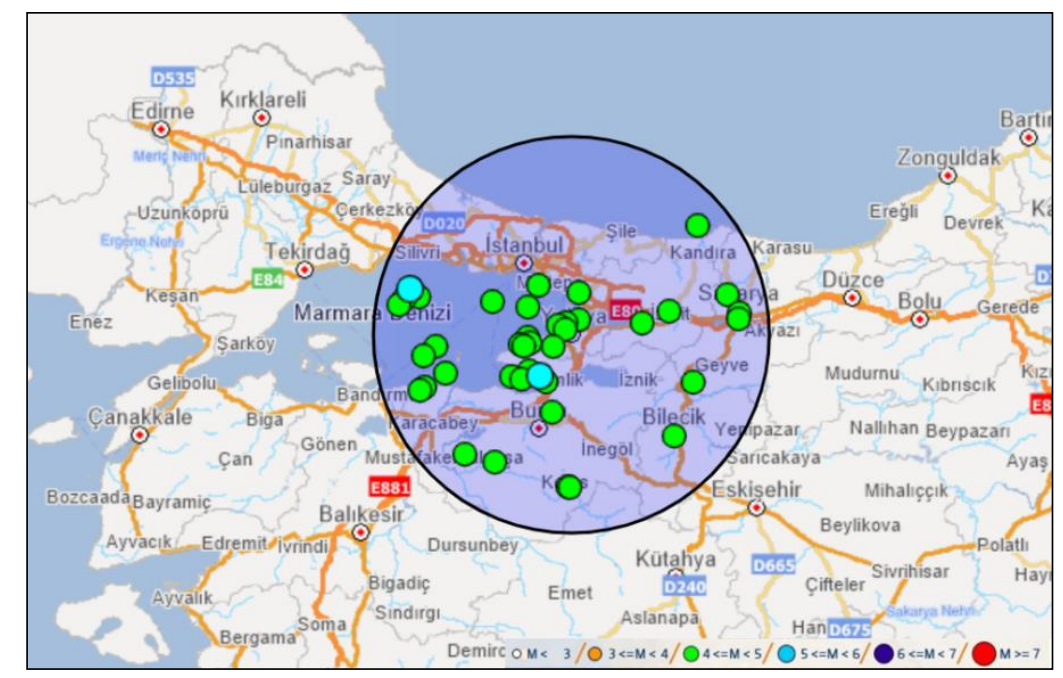

Figure. 2. Recorded earthquakes in the region after 1999 earthquakes (Afad, 2020).

The borings used for this study was in the middle of these fault lines in Yalova. It has been observed that the region has a highly active seismicity and a complex feature with the effect of these tectonic structures. Considering a $100 \mathrm{~km}$ radius of the 
studied area; total of 42 earthquakes have been recorded in different sizes after the 1999 earthquakes till today. The distribution of the earthquakes is presented in Figure 2. 40 of them are smaller than magnitude 5, 2 of them are between 5-6 magnitude (Afad, 2020). Two borings that were taken out of from the mentioned region are apart from each other almost $15 \mathrm{~km}$ and have the similar shear wave velocity profile. SPT tests were carried out at each drilling point and their values were obtained along the depth. These two drilling points are defined as Boring-1 (B-1) and Boring-2 (B-2). Figure 3 shows the SPT-N values of the logs. According to TEC 2018, $30 \mathrm{~m}$ should be examined in the upper part of the ground. There is a rigid bedrock after $30 \mathrm{~m}$. 


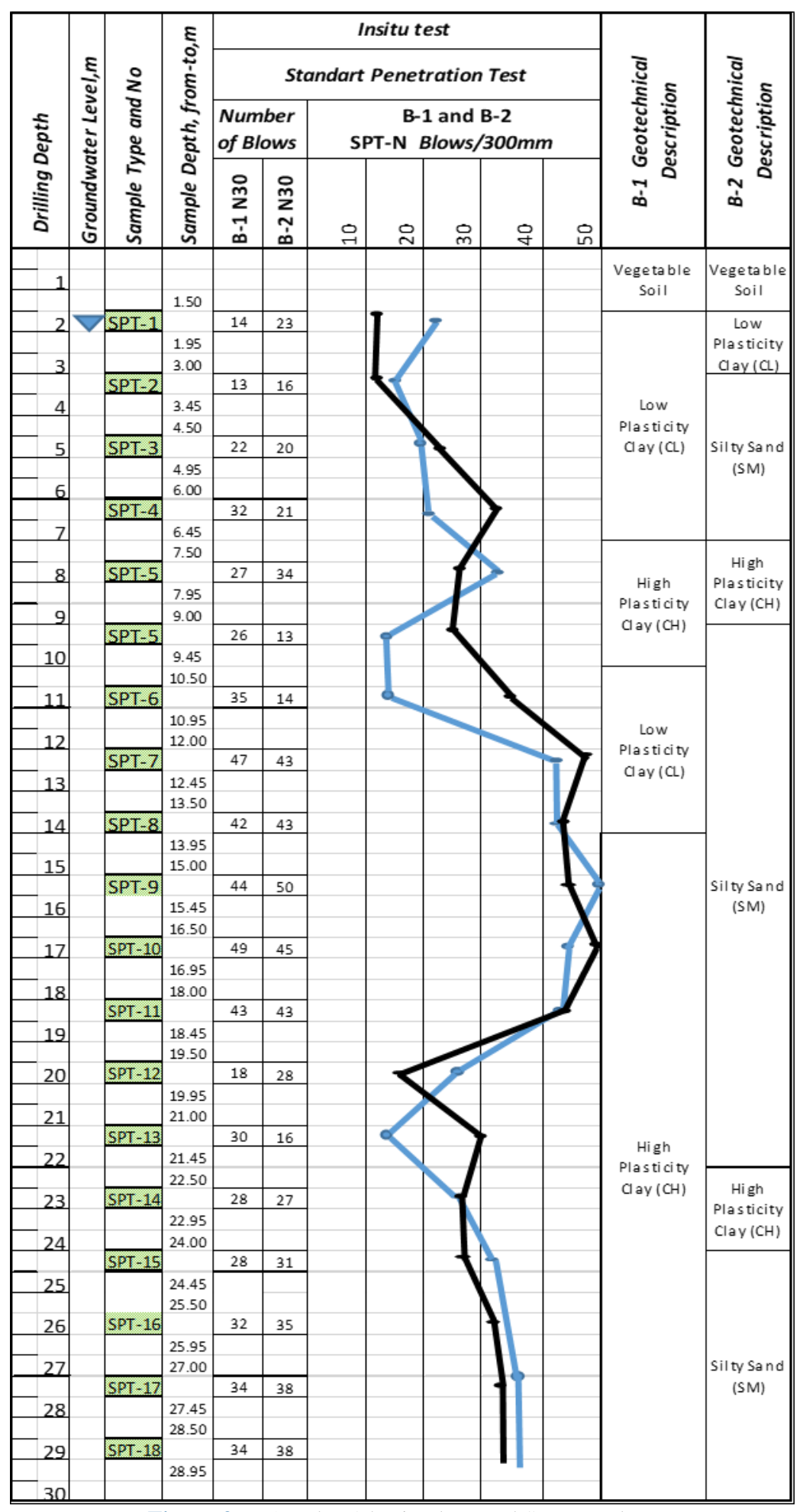

Figure 3. B-1 and B-2 boring logs and SPT-N values 
The soil profile consists of low and high plasticity of clay layers as given in the Figure 3 and the water table is at a shallow depth of $1.5 \mathrm{~m}$. Shear wave velocity (Vs) is an important feature of the soil layers to assess the dynamic properties for the seismic design and is directly related to shear modulus (initial rigidity). It can be determined from the samples both in the field with the seismic methods and in the lab from the dynamic tests. It is customary to know the change of S-wave velocity between $30 \sim 100 \mathrm{~m}$ depth for the site specific analysis as explained in the literature (Iyisan et al., 2016; Kurtuluş \& Stokoe, 2007, Ohta \& Goto, 1978). The shear wave velocity and the undrained shear strength $\left(\mathrm{s}_{\mathrm{u}}\right)$ profiles of the two borings are presented in Figure 4. The shear wave velocity profile was obtained by geophysical measurements conducted in the field. The average of shear wave velocity for upper $30 \mathrm{~m}$ of B-1 and B-2 were calculated as $214 \mathrm{~m} / \mathrm{s}$ and $215 \mathrm{~m} / \mathrm{s}$, respectively. The strength profile was obtained from the UU-tests conducted on the undisturbed samples.
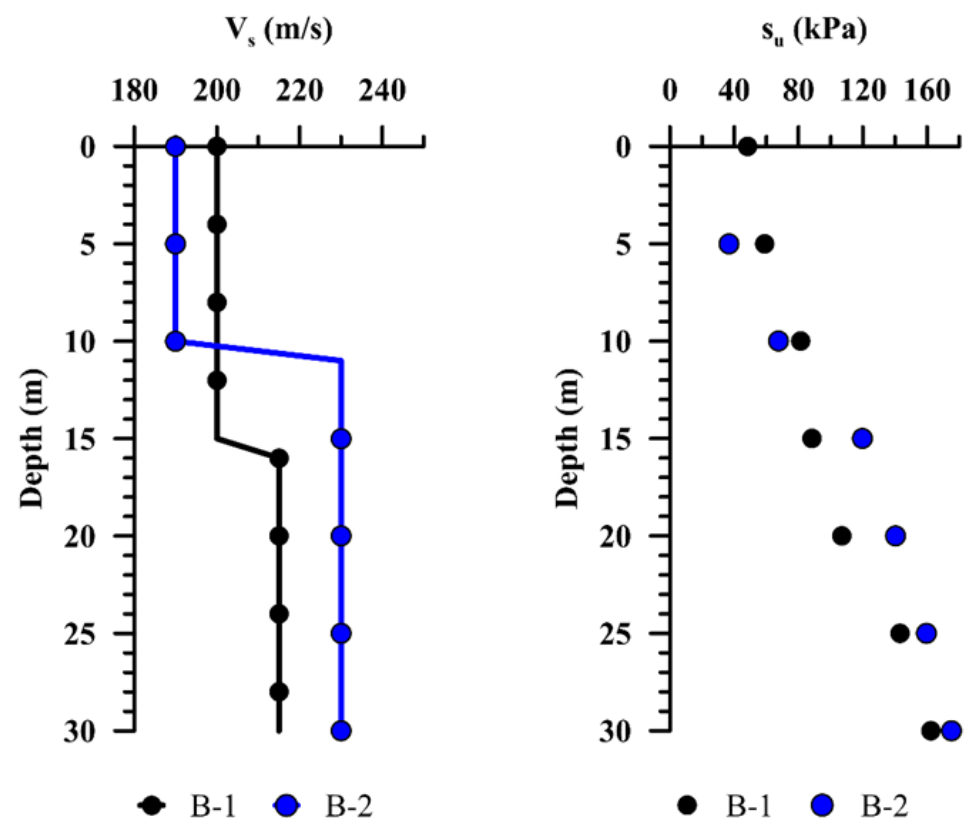

Figure 4. Shear wave velocity and undrained shear strength profiles.

As seen above, there is so much similarity in terms of the strength and shear wave velocity although there is about $15 \mathrm{~km}$ distance between the logs.

\subsection{Soil amplification analysis}

Site-specific analysis is an approach that accurately express the response of a soil column resulted from the seismic waves transmitted vertically in the interest of the design of the superstructure. It is only possible with the correct definition of local geology that takes into account the regional seismicity (Kramer, 1996). A soil profile can either amplify the base motion through the layers or de-amplify the seismic waves or transmit it as it is (i.e. rock behavior). The main purpose of the assessment of the amplification analysis is to accurately predict surface behavior for any earthquake scenarios in the region. There are two kinds of analyses that are used in the literature widely: a) equivalent linear and b) nonlinear analysis. Equivalent linear analysis is easy to conduct and not many specifications are needed whereas nonlinear analysis has a complex framework consisting of some parameters to constitute the dynamic behavior accurately. Both analyses were used in this study to be able to compare different approaches to estimate the ground behavior.

In this study, eleven earthquakes selected as a result of evaluations on different regulations were scaled in the frequency domain to almost $0.6 \mathrm{~g}$ which is the site specific value determined by the new Turkish Building Code for the earthquake motion level that is infrequent and the probability of the exceedance of the spectral magnitudes in 50 years is \%10 with a recurrence period of 475 years. Acceleration records used in the analyzes are shown in Figure 5. 

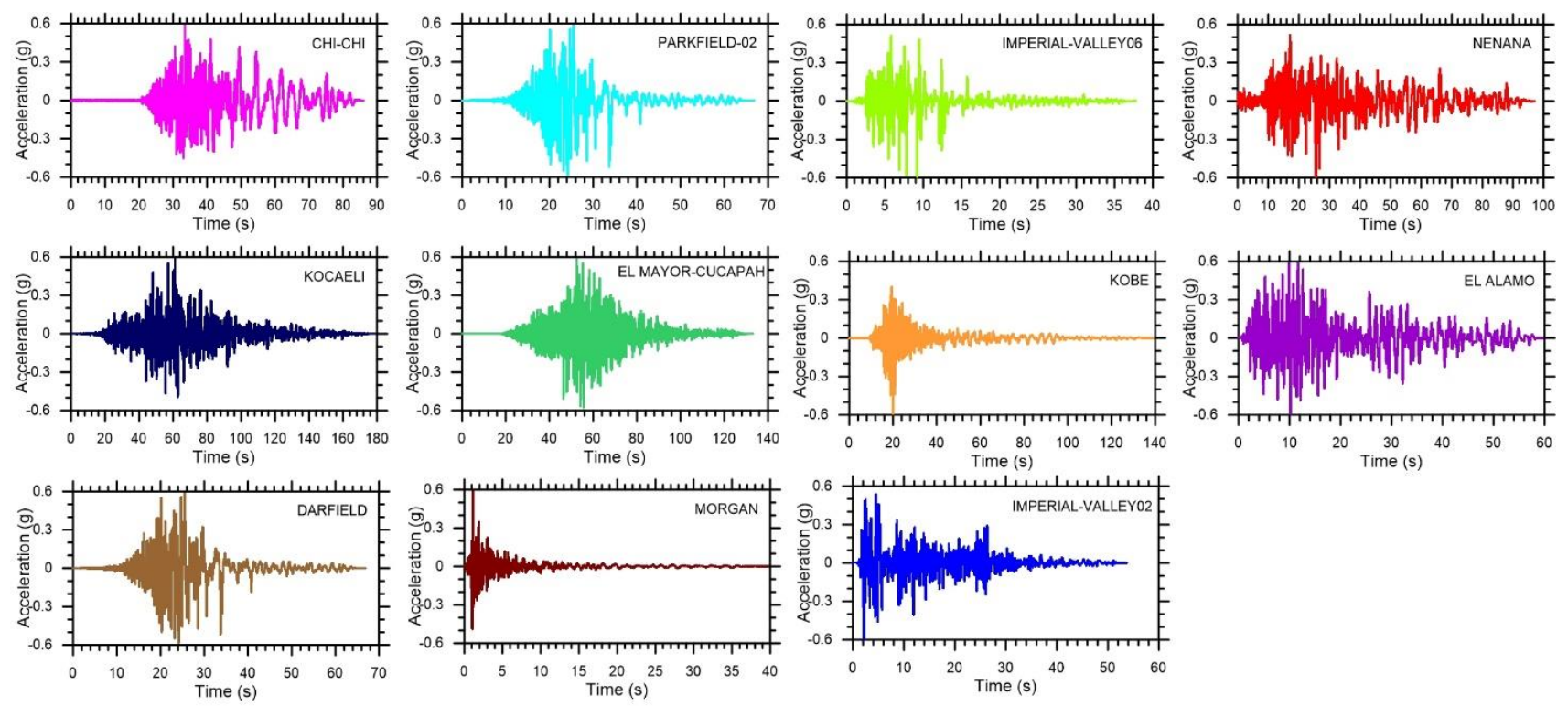

Figure 5. Scaled motions to be used as base input.

It is obvious from the figure that the acceleration time series differ from each other in the manner of the frequency content, duration and the number of the peaks over a certain acceleration value. Moreover, they would have different measure characteristics like arias intensity, cumulative absolute velocity, etc.

In order to understand the frequency variations, it is customary to detect the Fourier amplitude behavior over a range of frequency. Figure 6 shows the Fourier amplitude of the original (on the left) and scaled (on the right) versions of the selected motions. The variation of the peaks that points out the dominant frequency is very clear. For instance, the Chi-Chi record has an only and a sharp peak around $0.3 \mathrm{~Hz}$ whereas a wide range of dominant frequency content (between $0.3 \mathrm{to} 1 \mathrm{~Hz}$ ) was observed for the Nenana record. Some of the records are composed with different frequency components having almost none leading frequency as marked for the Parkfield record.
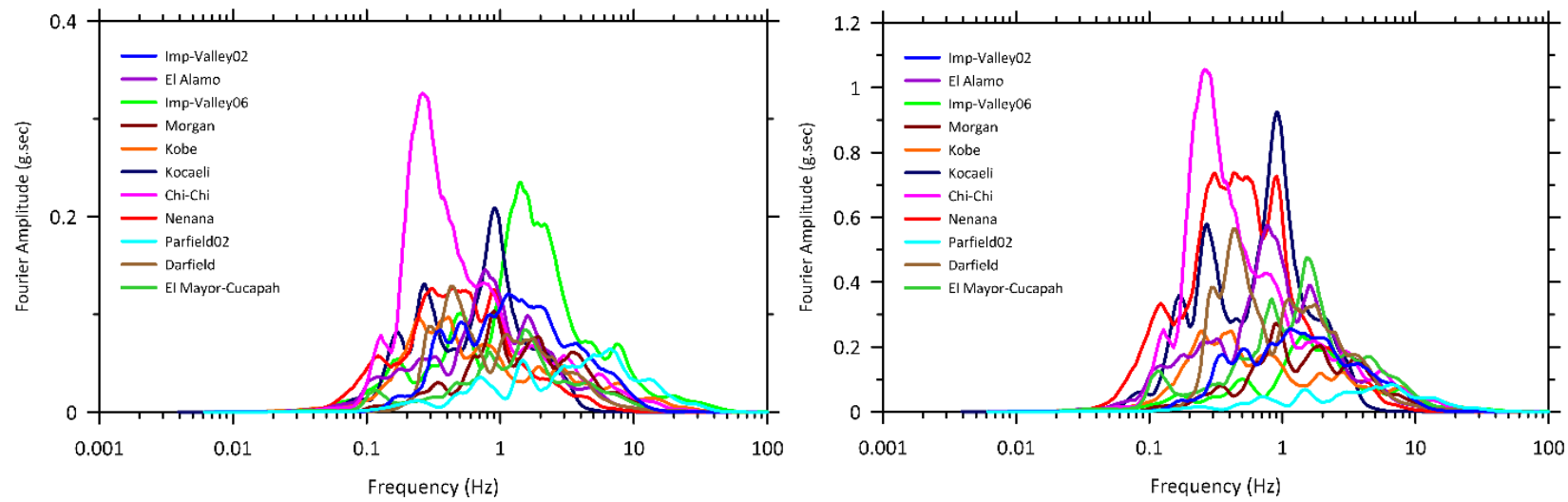

Figure 6. Fourier amplitude of the original and scaled motions used in the analysis.

The only thing they have in common is the peak acceleration that can also be seen in the response spectra of the records used in the analyses is presented in Figure 7. As the spectra of the motions start with a flat part, they begin separating and having peaks at different periods. Some records, such as Imperial Valley 06, Park Field 02 and Morgan, happen to have peaks at very short periods whereas some have them later like Kocaeli records. 
The main purpose here in this study was to constitute a group of motions that are diverse enough to estimate the site response in terms of variety characteristics of base motions.

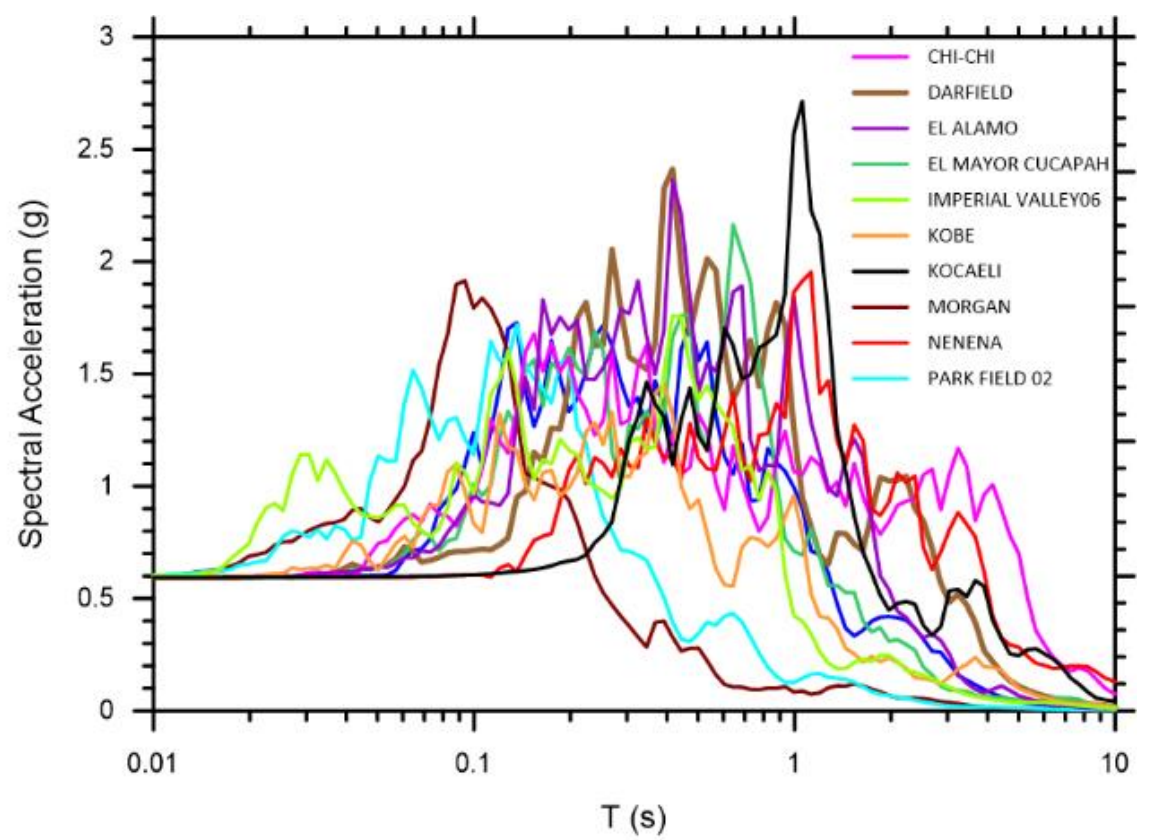

Figure 7. Spectral acceleration of the all earthquakes.

The boring logs defined in the DeepSoil v6.1 1-D analysis program were excited by 11 different motions at their bases made a total of 22 analyses. The site specifics were evaluated for both equivalent linear and non-linear methods. Both of them require some parameters to construct the soil column like shear wave velocity, the thickness of layer, etc. Another important part of the modeling is to frame the modulus reduction and damping behavior for each depth. For both sand and clay layers, Darendeli, 2001 was used to establish the dynamic behavior of the layers and the nonlinear backbone curves were generated using the General Quadratic/Hyperbolic Model proposed by Groholski et al. in 2016.

\section{Results}

\subsection{Findings from the 1-D site specific analysis}

Total of 44 analyses were performed on two boreholes that were obtained from an active earthquake zone with similar shear wave velocity profiles considering EL and NL approaches with the use of DeepSoil v6.1. In this part, two example results in terms of the spectral behavior will be presented first and then all the results will be discussed together along with the design spectra from different building codes. Finally, the behavioral change for different approaches will be examined.

\subsection{Example results from the models using the Chi-Chi and Darfield records as the base motions}

Out of 11 different records, two of them were selected to present the outcomes of the analysis and they are the scaled versions of the Chi-Chi and Darfield New Zealand earthquakes. The main reason they were chosen that the frequency content of those acceleration time series look similar at the first glance although the characteristics of the motions are different. The spectral behavior on the ground surface estimated from the analysis are shown in Figures 8 and 9. Both figures include the results of two borings under different approaches. It is also beneficial to introduce the bedrock (base) motion to be able to see the change through the soil layers. 
First thing to note is that the bedrock motion was de-amplified at almost any period for any borings with EL and NL approaches except the EL model at long periods (after $3 \mathrm{sec}$ ). Considering the ground spectral acceleration for non-linear models, the shapes of the spectra look very similar, the B-2 soil profile being the more de-amplifier of the base motion. Similar trend was detected for the equivalent linear models with the dominant hike of B-1 soil profile amplifying the base motion twice. The peak range of the base acceleration between $0.15 \mathrm{~s}$ to $0.32 \mathrm{~s}$ disappeared and transformed to the local spikes. The final point about the figure is that the B-2 soil profile is a unique profile since the ground surface behavior estimated from the EL and NL models match each other not too bad although one with a spike around $4 \mathrm{~s}$ whereas the other one has widen the pike between $1 \mathrm{~s}$ to $4 \mathrm{~s}$.

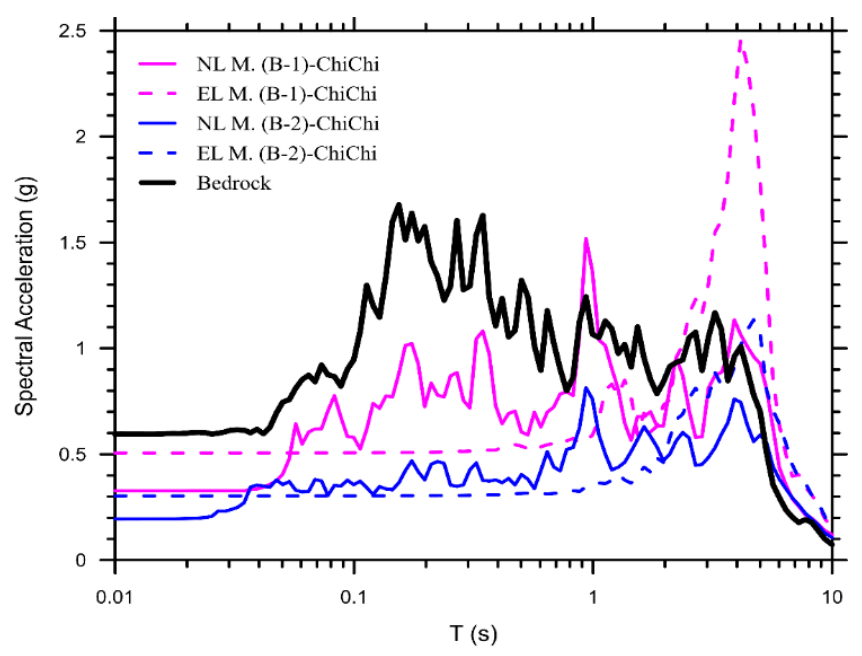

Figure 8. Spectral behavior of surface using the scaled Chi-Chi record as the base motion.

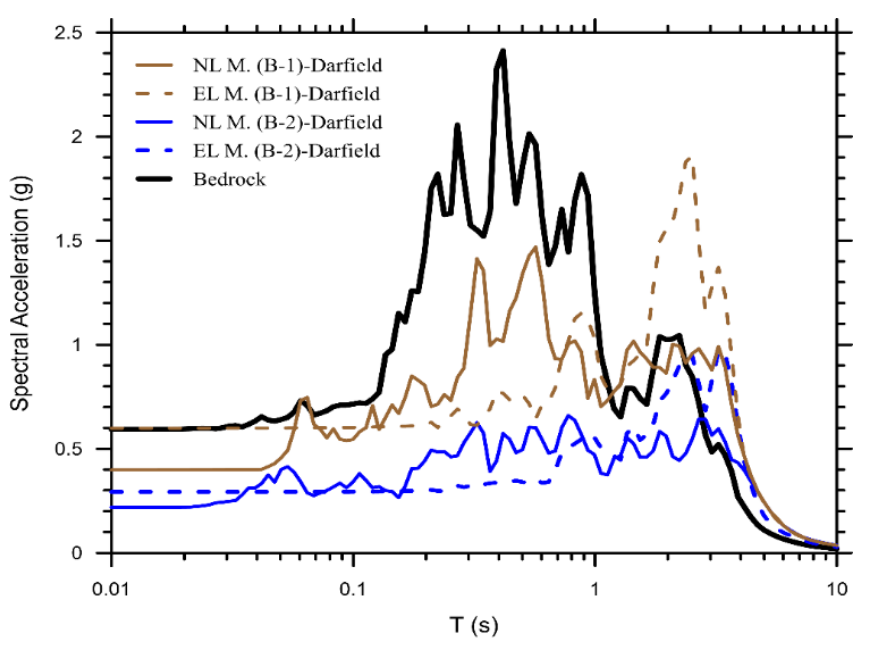

Figure 9. Spectral behavior of surface using the scaled Darfield record as the base motion

Just to see the possible distinct outcomes from varying models different bedrock motions, Figure 9 presents the spectral results observed from the model used the scaled Darfield record. The remarks are very similar here as the ones made for Figure 8. Additionally, the EL model of B-1 soil profile predicted the peak ground acceleration almost identical to the peak bedrock acceleration having a flat spectral behavior at short periods. Lastly, the peak base spectral acceleration was shifted and de-amplified by all the model in contrast to the models used the scaled Chi-Chi record.

In the design perspective, the ground spectral behavior is important to proportion the super-structure. However, the wave transmission through the soil column retain the significance for the geotechnical engineering sense. Thus, the variation of the 
peak acceleration values at the top of each layers were estimated as given in Figure 10 and 11 . It should be reminded here that all the base motions were scaled to the value of $0.593 \mathrm{~g}$ and the peak bedrock acceleration (PBA) was also shown in the figure.

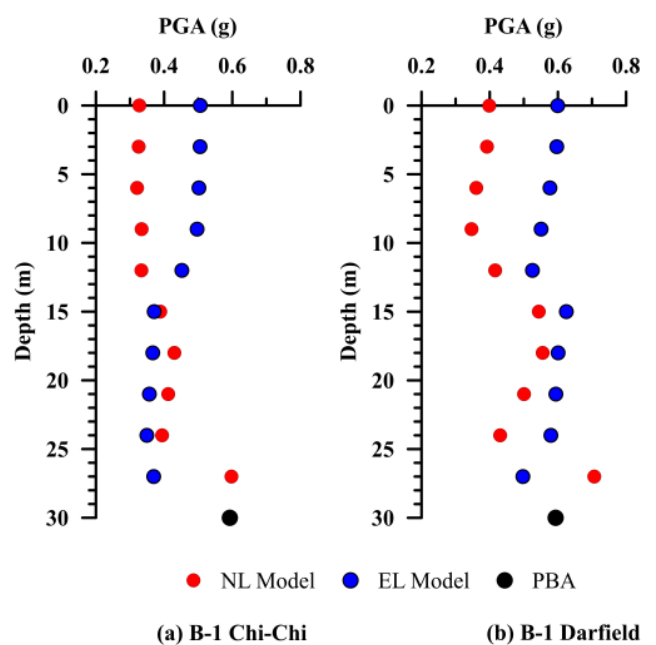

Figure 10. Variation of the PGA's though soil column for the B-1 boring.

Figure 10 proves that the amplitude of the bedrock motion of Chi-Chi record was damped out for all the layers regarding both EL and NL models whereas the bedrock motion of Darfield record was felt at similar amplitudes throughout the soil column for the EL model and de-amplified for the NL model.

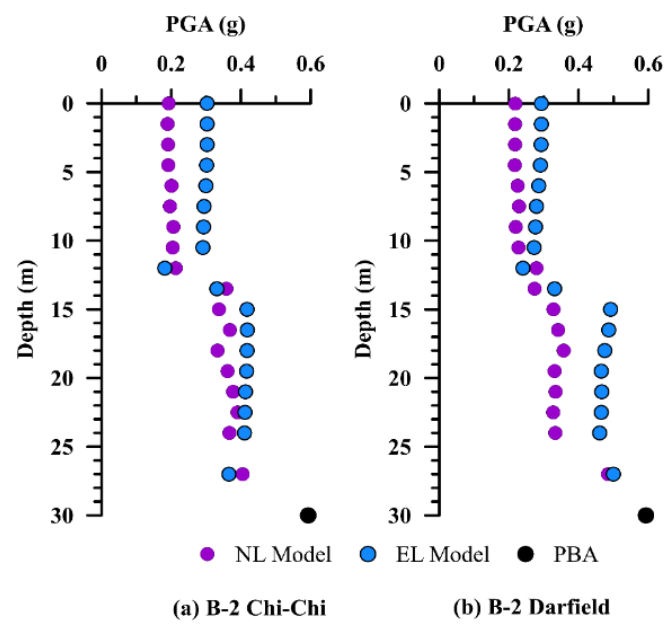

Figure 11. Variation of the PGA's though soil column for the B-2 boring.

Considering the B-2 log, the bedrock motions were lessened at any layer for EL and NL approaches. Besides, EL models predicted the peak acceleration more than NL models except couple the depths (13 $\mathrm{m}$ for both base excitations and $27 \mathrm{~m}$ for the scaled Chi-Chi record).

After pointing out the differences and similarities of the EL and NL models with utilizing the Chi-Chi and Darfield records, the next step will be assessing the total behavior resulted from the all motions as the building codes rule out for the site specific analysis. 


\subsection{Equivalent and nonlinear analyses comparison}

Conventionally, it is customary to evaluate the differential behavior from the equivalent analysis which is widely used in the literature and practice and the nonlinear analysis that needs more parameters to construct the nonlinearity of the soil dynamic behavior. Two distinct observations were made from the analyses in terms of the amplification factors through a wide range of period and the peak spectral accelerations.

Figure 12 presents the amplification behavior that can be describe as the ratio of the ground spectral acceleration over the base spectral acceleration. The maximum spectral accelerations seem to happen around 1 second among 11 different analyses. The rest of the spectral accelerations have their peaks later. We do not detect any general tendency to assess the amplifications. Two nonlinear models de-amplify the base motion at short periods whereas the equivalent model for the Boring-1 estimated similar peak ground accelerations with regard to the base motions but the other equivalent model also decrease the intensity of peak ground acceleration at short periods. Moreover, the behavior at longer periods after 1 second almost coincides with each other and not much difference was recognized.

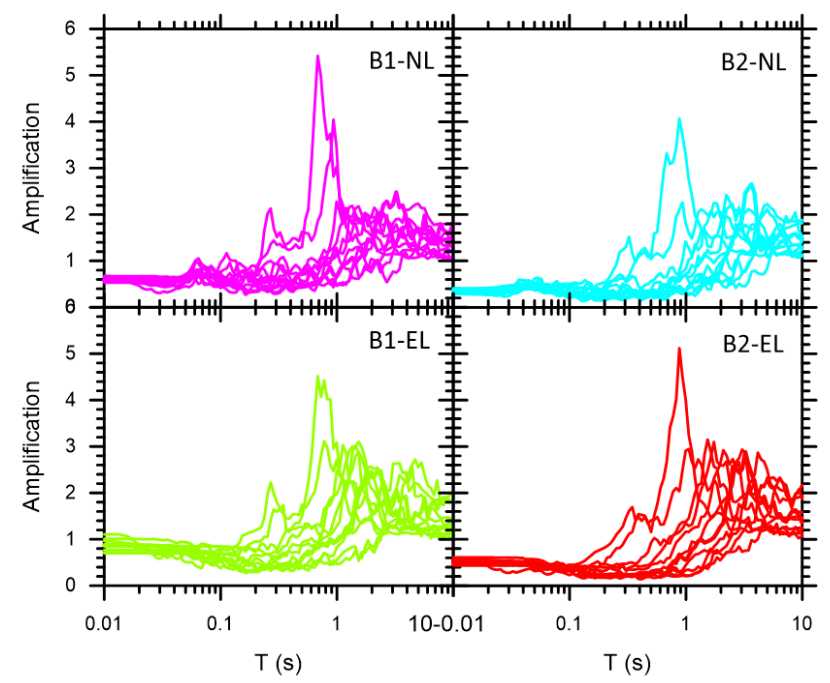

Figure 12. Amplification behavior comparison of equivalent and nonlinear analyses.

Moving to more detailed version of analogy between two different approaches, a direct comparison at short to medium periods are shown in Figure 13 (a), (b), and (c).
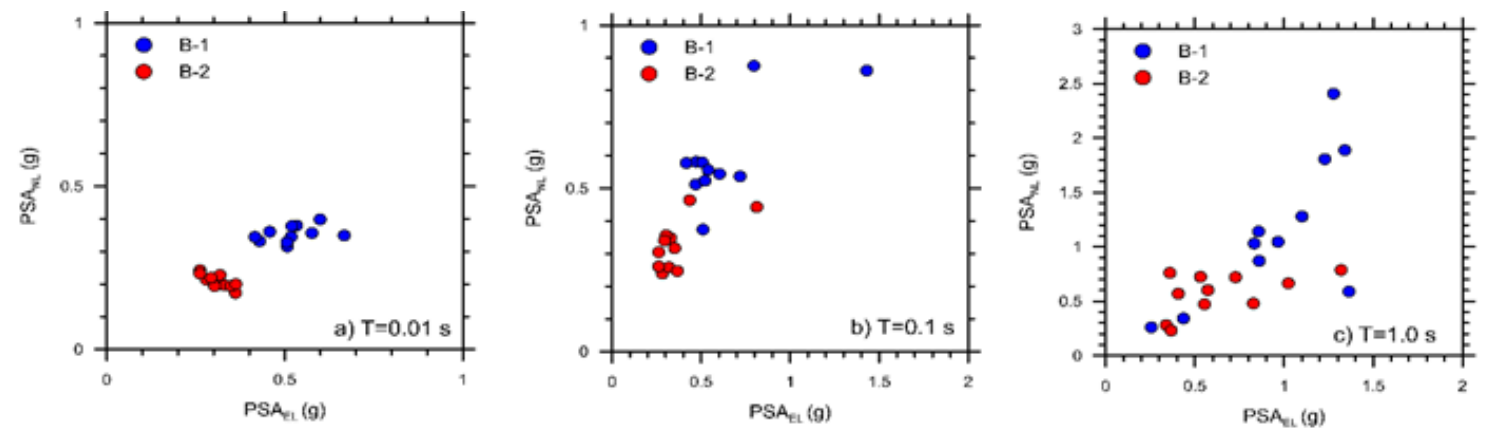

Figure 13. Spectral behavior comparison of two approaches at a) $\mathrm{T}=0.01 \mathrm{~s}$; b) $\mathrm{T}=0.1 \mathrm{~s}$; c) $\mathrm{T}=1.0 \mathrm{~s}$.

It is interesting to underline that at short periods the peak spectral behavior estimated from two different approaches for Boring 2 clustered around a small interval with a decreasing trend whereas there is a wider range for Boring 1 with an increasing tendency. Identical base motions excited to both profiles that have similar shear wave velocities with different soil 
microstructures totally resulted different site spectral behaviors at short periods as seen in Figure 13 (a). The distinction goes away for a higher period (Figure 13 (b)) and both soil profiles have higher peak spectral accelerations for equivalent linear models compared to nonlinear models. For $\mathrm{T}=1.0 \mathrm{~s}$., nonlinear models seem to produce similar spectral accelerations as the equivalent models do with a few outliers. Two absolute points can be outlined here that: 1) Equivalent and nonlinear models perform different at varying periods 2) The soil profile having different content develop diverse ground spectral behavior even if their shear wave velocities are almost the same. It proves that site specific analysis is a vital key to estimate the ground behavior. Last part will focus on the efficiency of the building codes regarding to the site specific analyses.

\subsection{Design spectra from the building codes versus site specific analyses}

Building codes regulate the rules that a designer should follow during the project of a building. Turkey is an earthquake prone country and seismic loads generally control the proportions of the frame elements. To do so, design spectrum is calculated from the regional building code. Generally, a few parameters are needed to establish the spectral behavior that are site specific numbers $\left(\mathrm{S}_{\mathrm{s}}, \mathrm{PGA}\right.$, etc.) and the soil classification depending on the average of $\mathrm{N}_{60}$, Vs, and cu over the upper $30 \mathrm{~m}$ of soil profile as mentioned earlier. It was also stated before that two borings apart from roughly $10 \mathrm{~km}$ from each other with almost identical shear wave velocity profiles were studied. The surface spectra of 44 different analyses accompanying with the design spectra evaluated from the new Turkish Building Code (2018) along with Eurocode (EC8) and International Building Code (IBC) are presented in Figure 14. The top side of the figure shows the results from the nonlinear models whereas the bottom is designated for equivalent linear models' results.

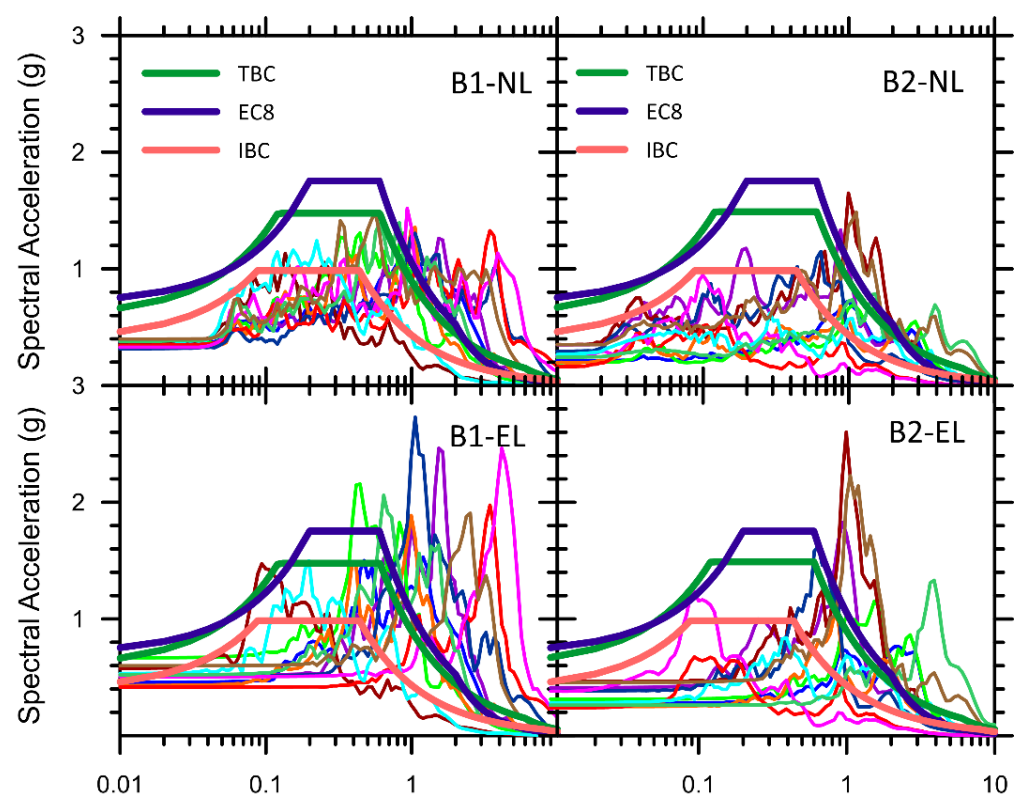

Figure 14. Comparison of design spectra of EL and NL analyzes with three regulations

Nonlinear models predict ground spectral accelerations on the safer side at short to medium periods compared to EC8 and TBC whereas the IBC design spectrum matches the spectral behavior of till $0.7 \mathrm{~s}$ alright, yet it underestimates the site specific behavior for the long period. Although there is a mismatch between the data with the EC8 and TBC, the long period behavior pair each other for the Boring 2. However, the discrepancy gets bigger for the Boring 1 after almost 1 second.

There is always a big discussion whether equivalent linear models or nonlinear models should be used in design purposes but it is beyond the scope of this study. What it is aimed here is that how the site specific results using equivalent linear models with the design spectra which is presented in the bottom of the figure. The distinction between the design spectra and the data at longer periods is now more obvious. No building codes does a good job to couple with the site specific results. Regarding the short to medium periods, Boring 2 site behavior stays under the EC8 and TBC even IBC but only short period spectral 
acceleration of Boring 1 match with the EC8 and TBC. Moreover, the flat parts of the building codes are not capable of the long period behavior.

One cannot miss the frequency content of the based motions used in the analyses but the soil having clayey or sandy structures throughout is profile causes differences in the surface spectral behavior that would certainly affect the design of the superstructure. This outcome is valid for both the equivalent linear and nonlinear approaches.

\section{Conclusions}

Site specific soil behavior analyses are performed to predict the behavioral change throughout the soil profile to be able to use it in design purposes. The index properties of the soil profiles have big influence on the transmission of the dynamic loads. Building codes are also handy to build the surface design spectrum instead of running site specific analysis. In this study, it is aimed to show that the building codes may not be capable of matching the site specific analyses results especially at longer periods. For this purpose, two different vertical downhole array with similar shear wave velocity and site class on a region near North Anatolian Fault are used. Eleven different earthquakes were chosen considering the similar fault type and the soil class. The spectral behaviors of the ground surface were obtained using equivalent linear and nonlinear approaches and they were compared with three different building codes and the observations are discussed as follows:

Frequency content is a key parameter in the site specific analyses and the selected motions have big influence on the construction of the design spectrum. There are different approaches to pick out the motions to be used in the analyses. In this case, we chose the earthquakes with the same fault type and the similar shear wave velocity profiles but again the variation is a lot in terms of the surface spectral behavior.

Three different building codes and their suggestions on the surface design spectra for a specific site were referred to compare the site specific analyses for both equivalent linear and nonlinear approaches. Even using the earthquakes having the same fault type, the building codes seem to miss the long period behavior for two different models. IBC just did a good prediction for the short period behavior but the variation is big for the rest of the periods. We did not expect the design spectra match the site specific analyses but one clear thing is that the flat part of the codes should be longer to better present the surface spectral accelerations.

Nonlinear and equivalent linear models produce different ground behavior since the approaches diverge at the damping behavior and the absorption of the energy through the soil particles from the bedrock to the surface. As mentioned in part 4.2, nonlinear models for two borings appear to de-amplify the base motions more compare to the equivalent linear models at any periods with couple exceptions. For these outliers, it is believed that the frequency content is the main reason. In addition, dynamic behavior of clays and sands are constituted on different engineering properties (i.e. plasticity index, relative density, etc.) so the conveyance of the wavelength differ a lot changing the surface behavior. There is a question arise from the discussion whether equivalent linear or nonlinear analyses should be used and there is no real answer. However, it is observed from the results that equivalent linear models contributed higher spectral behavior producing safer design spectrum whereas the nonlinear models depending on complex parameters construct more economical design.

Finally, the soil class concept solely relying on the average shear wave velocity misses the dynamic behavioral change of clayey and sandy soils. The vertical arrays used in this study can be considered unique since their shear wave velocity and SPT-N profiles are so similar. Boring 1 is classified as low plasticity clay for all the profile whereas Boring 2 consists of low plasticity, high plasticity clays with a big portion of silty sands. The granular soil seems to absorb some energy by the possible deformation during the excitation resulting less amplification at longer periods compared to the clayey soil. Building codes are very helpful and constitute a set of rules but site specific analyses should be considered in designs not only for ZF soils but for other soil classes when the soil profile is constructed very well. Last point is that the building codes omit the long period spectral acceleration and the corner frequencies should be updated considering the clayey and sandy behavior.

Conflicts of interest: On behalf of all authors, the corresponding author states that there is no conflict of interest. 
References

Afad. (2020). Disaster and Emergency Management Presidecy. https://www.afad.gov.tr

Alielahi, H., \& Adampira, M. (2016). Seismic effects of two-dimensional subsurface cavity on the ground motion by BEM: Amplification patterns and engineering applications. Int J Civ Eng. 14, 233-251. https://doi.org/10.1007/s40999-016-0020-7.

Aksoylu, C., Mobark, A., Arslan, M.H., \& Erkan, İ.H. (2020). A comparative study on ASCE 7-16, TBEC-2018 and TEC-2007 for reinforced concrete buildings. Revista de la Construcción. Journal of Construction. 19(2), 282-305.

Ansal, A., Tönük, G., \& Kurtuluş, A. (2011). Zemin Büyütme Analizleri ve Sahaya Özel Tasarım Depremi Özelliklerinin Belirlenmesi. 1.Turkey Earthquake Engineering and Seismology Conference:1-8.

Arslan, G., Borekci, M., Sahin, B., Denizer, MI., \& Duman, KS. (2018). Performance Evaluation of In-Plan Irregular RC Frame Buildings Based on Turkish Seismic Code. Int J Civ Eng. 16, 323-333. https://doi.org/10.1007/s40999-016-0131-1.

Bouckovalas GD, Tsiapas YZ, Theocharis AI, \& Chaloulos YK (2016) Ground response at lique fi ed sites: seismic isolation or amplification. 91, 329-339. https://doi.org/10.1016/j.soildyn.2016.09.028.

Choi, Y., \& Stewart, JP. (2005). Nonlinear site amplification as function of $30 \mathrm{~m}$ shear wave velocity. Earthq Spectra. 21, 1-30. https://doi.org/10.1193/1.1856535.

Darendeli, M. (2001). Development of New Family of Normalized Modulus Reduction and Material Damping Curves, PhD Thesis, Texas, USA.

Dikmen, S.Ü., \& Tan, G. (2018). Site amplification and resonance frequency in the urban environment. 105, 160-170. https://doi.org/10.1016/j.soildyn.2017.12.010.

Ebrahimi Motlagh, H.R., \& Rahai, A. (2017). Dynamic Response of a Continuous-Deck Bridge with Different Skew Degrees to Near-Field Ground Motions. Int J Civ Eng. 15, 715-725. https://doi.org/10.1007/s40999-017-0169-8.

EC8 EN 1998-1 (2004) Eurocode 8: design of structures for earthquake resistance—part 1: general rules, seismic actions and rules for buildings. European Committee for Standardization (CEN), Brussels.

Emre, Ö., Doğan, A., Duman T.Y., \& Özalp, (2011). 1:250,000 Scale Active Fault Map Series of Turkey, Bursa (NK 35-12) Quadrangle. Serial Number:9, General Directorate of Mineral Research and Exploration, Ankara-Turkey.

Fahjan, Y.M., (2008). Türkiye Deprem Yönetmeliği (DBYBHY, 2007) tasanm ivme spektrumuna uygun gerçek deprem kayıtlarının seçilmesi ve ölçeklenmesi (In Turkish). Tek Dergi/Technical J Turkish Chamb Civ Eng. 19, 4423-4444.

Fahjan, Y.M., (2008). Selection and scaling of real earthquake accelerograms to fit the Turkish design spectra. Tek Dergi/Technical J Turkish Chamb Civ Eng. 19, 1231-1250.

Groholski, D., Hashash, Y., Kim, B., Musgrove, M., Harmon, J., \& Stewart, J. (2016). Simplified Model for Small-Strain Nonlinearity and Strength in 1D Seismic Site Response Analysis. J. Geotech. Geoenviron. Eng.

Habibi, A., \& Jami, E. (2017). Correlation Between Ground Motion Parameters and Target Displacement of Steel Structures. Int J Civ Eng 15, $163-174$. https://doi.org/10.1007/s40999-016-0084-4.

Harmon, J., Eeri, M., Hashash, Y.M.A., Eeri, M., Stewart, J.P., Eeri, M., et al. (2019). Site Amplification Functions for Central and Eastern North America - Part I : Simulation Data Set Development. 35, 787-814. https://doi.org/10.1193/091017EQS178M.

Harmon, J.A., Eeri, M., Parker, G.A., Eeri, M., Stewart, J.P., Eeri M, et al. (2020). Nonlinear site amplification model for ergodic seismic hazard analysis in Central and Eastern North America. https://doi.org/10.1177/8755293019878193.

Hashash, Y. M. A., Musgrove, M. I., Harmon, J. A., Groholski, D., Phillips, C. A. \& Park, D. (2016). DEEPSOIL V6.1, User Manual. Urbana, IL, Board of Trustees of University of Illinois at Urbana-Champaign.

Horri, K., \& Mousavi, M. (2019). Modeling and studying the impact of soil plasticity on the site amplification factor in ground motion prediction equations. J Seismol. 23, 1179-1200. https://doi.org/10.1007/s10950-019-09871-w

Iyisan, R., Hatipoglu, M., \& Ozudogru, T.Y. (2016). Kayma Dalgası Hızının PS Logging Yöntemi ile Belirlenmesi (Determination of Shear Velocity by Suspension PS Logging Method) 16th Conf of Soil Mechanic and Geotechnical Engineering.

IBC, (2018). The International Building Code Whittier, CA.

Kaptan, K., \& Tezcan, S. (2012). Deprem dalgalarinin zemin büyütmesi üzerine örnekler Turkısh Science-Research Foundation 4, 17-32.

Kramer, S.L. (1996). Geotechnical Earthquake Engineering, Prentice Hall, Upper Saddle River, New Jersey, U.S.A.

Kayhan, A.H. (2012). Armoni Araştırması ile İvme Kaydı Seçimi ve Ölçeklendirme (In Turkish). İMO Teknik Dergi 368, 5751-5775.

Koç, G. (2007). Gölcük ve Çevresinin Sıvılaşma Potansiyelinin Değerlendirilmesi (In Turkish). Master thesis. Kocaeli University. 
Kurtuluş, A, \& Stokoe, K.H. (2007). Zeminin doğrusal olmayan kayma modülünün arazide belirlenmesi (In Situ Evalution of Nonlinear Shear Modulus of Soil). Sixth National Conference on Earthquake Engineering 459-470.

Liu, L., \& Dobry, R. (1997). Seismic response of shallow foundation on liquefiable sand. J Geotech Eng.123, 557-566. https://doi.org/10.1061/(asce)10900241(1997)123:6(557)

Ohta, Y., \& Goto, N. (1978). Empirical shear wave velocity equations in terms of characteristic soil indexes. Earthq Eng Struct Dyn. 6, $167-187$. https://doi.org/10.1002/eqe.4290060205.

Özdemir, Z., \& Fahjan, Y.M. (2007). Comparison of Time and Frequency Domain Scaling of Real Accelerograms to Match Earthquake Design Spectra. Sixth Natl Conf Earthq Eng. 435-446.

PEER. (2019), Pacific Earthquake Engineering Research Center, Strong Motion Database, https://ngawest2.berkeley.edu.

Pitilakis, K., Riga, E., \& Anastasiadis, A. (2012). Design spectra and amplification factors for Eurocode 8. Bull Earthq Eng. 10, 1377-1400. https://doi.org/10.1007/s10518-012-9367-6.

Pitilakis, K., Riga, E., \& Anastasiadis, A. (2013). New code site classification, amplification factors and normalized response spectra based on a worldwide ground-motion database. Bull Earthq Eng. 11, 925-966. https://doi.org/10.1007/s10518-013-9429-4.

(요요

commercial-No Derivatives 4.0 International License. 